\title{
Trichophyton rubrum
}

National Cancer Institute

\section{Source}

National Cancer Institute. Trichophyton rubrum. NCI Thesaurus. Code C127754.

A species of anthropophilic and dermatophytic fungi in the phylum Ascomycota. This species causes chronic infections of skin, nails, and rarely scalp. 